\title{
Microencapsulation of Lactobacillus plantarum DKL 109 using External Ionic Gelation Method
}

\author{
Honam Chun ${ }^{1}$, Cheol-Hyun Kim, and Young-Hee Cho* \\ Department of Animal Resource \& Science, Dankook University, Cheonan 330-714, Korea \\ ${ }^{1} R \& D$ Center, Danone Pulmuone Co., Seoul 136-701, Korea
}

\begin{abstract}
The aim of this study was to apply the external ionic gelation using an atomizing spray device comprised of a spray gun to improve the viability of Lactobacillus plantarum DKL 109 and for its commercial use. Three coating material formulas were used to microencapsulate L. plantarum DKL 109: 2\% alginate (Al), 1\% alginate/1\% gellan gum (Al-GG), and 1.5\% alginate/3\% gum arabic (Al-GA). Particle size of microcapsules was ranged from 18.2 to $23.01 \mu \mathrm{m}$ depending on the coating materials. Al-GA microcapsules showed the highest microencapsulation yield (98.11\%) and resulted in a significant increase in survivability of probiotic in a high acid and bile environment. Encapsulation also improved the storage stability of cells. The viability of encapsulated cells remained constant after 1-mon storage at ambient temperature. The external ionic gelation method using an atomizing spray device and the Al-GA seems to be an efficient encapsulation technology for protecting probiotics in terms of scale-up potential and small microcapsule size.
\end{abstract}

Keywords: probiotics, Lactobacillus plantarum, external gelation, atomizing spray device

\section{Introduction}

Nowadays, consumers are aware that lifestyle, diet, and good health are linked, which leads to a demand for products to enhance health beyond providing basic nutritional value (Soccol et al., 2010). The list of health benefits accredited to functional food continues to increase, and functional food containing probiotics is one of the fastest growing categories in the marketplace because of the health benefits ascribed to probiotics when consumed in proper amounts (Gerez et al., 2012). Probiotics are considered as being "live microorganisms which administered in adequate amounts, can confer a beneficial physiological effect on the host" (Dong et al., 2013).

To exert their biological effects on the host, some of the most important considerations of probiotic bacteria are their viability and activity. As a guide, the International Dairy Federation has recommended a minimum of $10^{7}$ $\mathrm{CFU} / \mathrm{g}$ of the products to the date of minimum durability (Chandramouli et al., 2004; Dong et al., 2013). However, probiotic cells may not survive in sufficient numbers when

*Corresponding author: Young-Hee Cho, Department of Animal Resource and Science, Dankook University, Cheonan 330-714, Korea. Tel: +82-41-550-3658, Fax: +82-41-622-2207, E-mail: yhcho@dankook.ac.kr incorporated into dairy products and also during their passage through the gastro-intestinal tract because of their low resistance to various environmental factors (e.g., $\mathrm{pH}$, post-acidification in fermented products, oxygen toxicity, and storage temperature) and to the stressful conditions of the stomach $\mathrm{pH}$ and bile salts in the upper intestine (Martin et al., 2013; Shi et al., 2013; Song et al., 2003). Moreover, when incorporating a probiotic strain into a food matrix, there are another problem to be addressed: the resistance of the probiotic to the technological conditions of the food production and the maintenance of viability up to the expiring date of the food (Martin et al., 2013).

Even though several ways to enhance probiotic viability have been studied, encapsulation is still regarded as one of most useful methods to increase the viability of probiotic cells in the gastrointestinal tract and to protect probiotics during processing and subsequent storage in food products. Many encapsulation methods developed for probiotics generally involve entrapment in hydrocolloid beads, which is also known as an ionic gelation method. This method is based on the ability of ionic polymers, such as alginate, carrageenan, and gellan gum, to cross link by electrostatic interaction between oppositely charged species to form hydrogel beads (Nayak et al., 2012; RosasFlores et al., 2013; Sohail et al., 2013). This encapsulation technique is classified into two groups depending on 
the method used to form the beads: extrusion (droplet method) and emulsion (two-phase system), also called external ionic gelation and internal ionic gelation techniques, respectively (Krasaekoopt et al., 2003). This technique is simple, fast, and low cost. Moreover, the conditions used are very mild, as physical cross-linking by ionic gelation avoids the possible toxicity of reagents and other undesirable effects (Nayak et al., 2012).

Although several studies have revealed that both extrusion and emulsion methods increase the survival of probiotic cells, most results are only promising in a laboratory scale. The extrusion/external ionic gelation method faces many challenges for scaling-up of the process and application on an industrial scale because of its low production capacity, limitation of size reduction, and uneven capsule formation (Dong et al., 2013; Picot and Lacroix, 2004). The emulsification/internal gelation method has been suggested as an alternative for the formation of spherically structured capsules with sizes of less than $1,000 \mu \mathrm{m}$ and it is easy to scale up (Rosas-Flores et al., 2013). However, this technique is limited to batch production and has difficulty in the removal of the oil, which requires chemicals and other separation steps (Sohail et al., 2011).

The coating material is also a key factor in developing successful microencapsulated probiotics. The most widely used matrix for the microencapsulation of probiotics is alginate, a polyanionic copolymer of mannuronic and guluronic acid residues, due to its simplicity, non-toxicity, biocompatibility, low cost, and ionotropic gelation property (Chandramouli et al., 2004; Dong et al., 2013; Zou et al., 2012). However, the use of alginate is limited due to its low physical stability in the presence of monovalent ions or chelating agents, and harsh environmental conditions (Dong et al., 2013; Martin et al., 2013). The encapsulation effectiveness of different probiotics has been improved through co-encapsulation with other compounds, coating the beads with another polymer or modifying of alginate structure using different additives (Kanmani et al., 2011; Krasaekoopt et al., 2004; Martin et al., 2013; Rosa-Flores et al., 2013; Sohail et al., 2013). Therefore, alginate was blended with other polymers to improve the ionic-gelled capsules for probiotic encapsulation in this study.

Probiotic microorganisms are mostly of human or animal origin, but there is increasing interest in probiotics isolated from non-dairy fermented foods and their application in dairy products (Cho et al., 2013). In previous research (Cho et al., 2013), several lactic acid bacteria strains were isolated from kimchi, Korean traditional fermented vegetable, and four of these strains were selected to study their characteristics for commercial use as probiotics and starter cultures in dairy products. Of them, Lactobacillus plantarum DKL 109 showed a potential as a starter culture but had low resistance to acid and bile salt.

As mentioned above, the major drawbacks of extrusion/ external ionic gelation are limitations in size reduction and industrial scale-up, as it requires a large number of nozzles to be operated simultaneously. Several techniques, such as the use of multiple needles, electrostatics and vibration, have been developed to solve these problems (Reis et al., 2006). Atomizing spray techniques were investigated to produce smaller microcapsules at higher rates. We designed an atomizing spray device comprised of an air spray gun to reduce capsule size, increase the ease of mass production, and consequently apply in a pilot scale. The aim of this study was to evaluate the application of this technique and coating materials for the encapsulation of the probiotic L. plantarum DKL 109, and the survivability of the encapsulated probiotic cells in low $\mathrm{pH}$ and bile salts under simulated gastrointestinal conditions and the stability of the cells during storage.

\section{Materials and Methods}

\section{Materials}

Na-alginate and gum Arabic were supplied by MSC Co. (Korea). Gellan gum (CP Kelco) was provided from Jupiter (Korea). Milk casein (FE 135) and yeast extract (Plus LS) were obtained from DMV (Netherlands) and DSM (Korea), respectively. MRS broth was purchased from Difco (Sparks, USA). All other chemicals were purchased from Junsei Co. (Japan).

\section{Microorganism and culture conditions}

Lactobacillus plantarum DKL 109 isolated from kimchi samples was maintained in glycerol stocks at $-20^{\circ} \mathrm{C}$. Table 1 showed the composition of the specific culture media. All the ingredients listed in Table 1 were dissolved in distilled water, and then $\mathrm{pH}$ was adjusted to 6.5. The freeze-dried culture was subcultured twice in MRS broth at $37^{\circ} \mathrm{C}$ for $12 \mathrm{~h}$ under aerobic conditions. The culture was harvested by centrifugation at $3,000 \mathrm{~g}$ for $20 \mathrm{~min}$, and the cell pellets were washed twice with distilled water. Finally, the cells were enumerated by inoculating in specific culture media and incubated at $37^{\circ} \mathrm{C}$ for $24 \mathrm{~h}$. The final cell concentration was adjusted to $10^{10} \mathrm{CFU} / \mathrm{mL}$. 
Table 1. Composition of growth media

\begin{tabular}{cc}
\hline \hline Ingredients & $\%$ \\
\hline Dextrose & 0.5 \\
Lactose & 0.5 \\
Yeast Extract (Plus LS) & 1.5 \\
Milk casein (DMV FE135) & 2.5 \\
$\mathrm{MgSO}_{4}$ & 0.01 \\
$\mathrm{MnSO}_{4}-\mathrm{H}_{2} \mathrm{O}$ & 0.005 \\
Ascorbic acid & 0.01 \\
Na-acetate & 0.3 \\
Na-citrate & 0.1 \\
$\mathrm{~K}_{2} \mathrm{HPO}_{4}$ & 0.2 \\
\hline
\end{tabular}

\section{Microcapsule preparation}

The microcapsules containing probiotics were prepared by external ionic gelation technique using an atomizing spray device comprised of an air spray gun (EZ-Bio, Korea). Through a preliminary study, three formulations of coating material were selected: $2 \%$ alginate $(\mathrm{Al}), 1 \%$ alginate $+1 \%$ gellan gum (Al-GG), and $1.5 \%$ alginate $+3 \%$ gum Arabic (Al-GA). L. plantarum DKL 109 culture grown in specific media was harvested by centrifugation at $3,000 \mathrm{~g}$ for $20 \mathrm{~min}$, and the pellet was resuspended in $0.85 \%$ saline. Then 1 part of cell suspension $(10.7 \mathrm{Log}$ $\mathrm{CFU} / \mathrm{mL}$ ) was mixed with 3 parts of coating material and blended with a homomixer (IKA, Japan) at 10,000 rpm for $10 \mathrm{~min}$. The mixture was poured into the inlet reservoir of an air spray gun with $1.3 \mathrm{~mm}$ diameter nozzle. The spray gun was connected to an air compressor and operated at an air pressure of $0.2 \mathrm{MPa}$. Then the mixture was sprayed into a $2 \%$ calcium chloride solution under gentle stirring with a magnetic bar. The resulting microcapsule was obtained by centrifugation at $3,000 \mathrm{~g}$ for $5 \mathrm{~min}$ followed by washing twice with distilled water. Reconstituted milk $(10 \%)$ was mixed with the microcapsule slurry, and then the microcapsules were frozen at $-70^{\circ} \mathrm{C}$ for $1 \mathrm{~h}$ and freeze dried for $24 \mathrm{~h}$ using a freeze dryer (Ilshin BioBase, Korea). The resulting freeze-dried microcapsules were packed in $100 \mathrm{~mL}$ sterilized, airtighted, and capped bottles and stored in desiccators.

\section{Enumeration of microencapsulated bacteria}

To determine the viable counts of the encapsulated cells, $1 \mathrm{~g}$ of microcapsules was resuspended in $100 \mathrm{~mL}$ of phosphate buffer $(0.1 \mathrm{M}, \mathrm{pH}$ 7.1) followed by gentle shaking for $20 \mathrm{~min}$ at room temperature. A 1-mL aliquot of suspension was removed, serially diluted with $0.85 \%$ saline, and then inoculated on MRS agar plates. All plates were incubated at $37^{\circ} \mathrm{C}$ for $48 \mathrm{~h}$.

\section{Encapsulation yield}

Encapsulated cells were released from capsule as described above. All samples were analyzed in triplicate. The encapsulation yield (EY), a combined measurement of the efficacy of entrapment and survival of viable cells during encapsulation (Martin et al., 2013), was calculated as follows:

$$
\mathrm{EY}=\left(\mathrm{N} / \mathrm{N}_{0}\right) \times 100
$$

where $\mathrm{N}$ is the number of viable cells released from microcapsules and $\mathrm{N}_{0}$ is the number of free cells added to the coating materials during the encapsulation process.

\section{Particle size}

The particle distribution and mean particle size were analyzed using a laser diffraction particle size analyzer (SALD-2001, Shimadz, Japan). All samples were analyzed in triplicate.

\section{Morphological analysis}

The cell distribution in the microcapsules and the shape of the microcapsules after freeze-drying were observed using an optical microscope (BX 51TF, Olympus Co., Japan). For ease of observation through the optical microscope, the cells were dyed with crystal violet before the encapsulation procedure. The shape and microstructural properties of the freeze-dried microcapsules were investigated with a scanning electron microscope (JSM-6510, Jeol Co., Japan). The samples were mounted on metal stubs with two-sided adhesive tape and coated with gold in an ion sputter ( $\varepsilon-1030$, Hitachi, Japan) for $165 \mathrm{~s}$ at 15 $\mathrm{mA}$ under an argon atmosphere.

\section{Survival of microencapsulated cells after sequen- tial incubation in artificial gastric juice (AGJ) and artificial intestinal juice (AIJ)}

For the preparation of AGJ, MRS broth was adjusted to $\mathrm{pH} 2.0$ with $1.0 \mathrm{~N} \mathrm{HCl}$. AIJ (pH 7.0) was prepared by the addition of $1 \%$ oxgall into MRS broth. Microencapsulated cells $(1 \mathrm{~g})$ and free cells $(1 \mathrm{~g})$ were added separately to conical tubes containing $10 \mathrm{~mL}$ of AGJ of pH 2.0 and incubated at $37^{\circ} \mathrm{C}$ for $2 \mathrm{~h}$ with gentle shaking using a shaker (SI-300R, JEIO Tech., Korea). After incubation, the microcapsules were subsequently placed in $10 \mathrm{~mL}$ of AIJ. The conical tubes were then incubated at $37^{\circ} \mathrm{C}$ for 3 $\mathrm{h}$ with gentle shaking. Aliquots $(1 \mathrm{~mL})$ of free and encapsulated cells were collected at $1 \mathrm{~h}$ intervals. The cells were serially diluted with $0.85 \%$ saline and inoculated on 
MRS agar plates. All the plates were incubated at $37^{\circ} \mathrm{C}$ for $48 \mathrm{~h}$. At every $1 \mathrm{~h}$ interval, samples were withdrawn and the morphological shape of the cells was observed under the optical microscope.

\section{Storage stability}

The encapsulated cells and free cells were stored at ambient temperature $\left(25^{\circ} \mathrm{C}\right)$ and $37^{\circ} \mathrm{C}$ for $4 \mathrm{wk}$. Survivability of the encapsulated cells and free cells was monitored at $1 \mathrm{wk}$ intervals. The viable cell counts were determined using the method previously described.

\section{Statistical analysis}

Tests were carried out in triplicate for all experiments. All data were presented as mean \pm standard deviations ( $\mathrm{S}$. D). Statistical comparisons were made using SAS version 9.0 (SAS Institute Inc., Cary, USA). Significant differences between treatments were tested by analysis of variance (ANOVA) followed by a comparison between treatments performed using Duncan's multiple range tests. Significance was defined at the $5 \%$ level.

\section{Results and Discussion}

\section{Improvement of cell viability}

A strain is commercially demanded for its technological and health properties. Therefore, the search for new technologies and culture media that enable high cell yield at a large scale is required because many strains of intestinal or vegetable origin are difficult to propagate. In addition, increased efficiency could lead to greater product efficacy and strain diversification (Soccol et al., 2010). L. plantarum DKL 109 showed low growth characteristics in standard Lactobacillus media, which may be due to its vegetable origin. In the preliminary study, factors influencing growth and cell count in different media were investigated to improve the commercialization potential of this strain. For high cell yield of selective probiotics, the modified media were prepared from individual ingredients in the laboratory. MRS agar was used as a basal medium, in which glucose was substituted with lactose and protein source was changed through the preliminary study
(Table 1). The growth of probiotic L. plantarum DKL 109 was enhanced by $2 \operatorname{logs}$ in specific culture medium (10.7 Log CFU/mL) than in standard MRS (8.7 Log CFU/mL).

\section{Microcapsule characteristics}

The selection of appropriate coating materials decides the physical and chemical properties of the resultant microcapsules (Agnihotri et al., 2012). As shown in Table 2 , the cell suspension used for encapsulation contained 10.4 Log CFU/mL and the number of cells in alginate capsule prepared using the atomizing spray device was in the range of 10.06-10.18 Log CFU/mL. As compared with the initial free cell load, very high cell loading in microcapsules was observed. Reis et al. (2003) indicated that atomizing spray techniques can be harmful to many biological encapsulants because of its shearing effects, but the device used in this study was found to be suitable for the probiotic encapsulation. The particle size of microcapsules containing L. plantarum DKL 109 varied from a minimum $18.41 \mathrm{~mm}$ to a maximum value of $20.87 \mathrm{~mm}$. Even though Al-GA microcapsule showed the larger particle size, the type of coating materials had no significant influence on the size of the microcapsules containing probiotics. The viability of the probiotics was evaluated for every formula to identify the most effective combination of coating materials. Table 2 showed the number of cells encapsulated in each formula of coating materials and their EY. Microencapsulation in Al-GA was the most appropriate for microencapsulation of L. plantarum DKL 109 because it showed the highest EY and cell loading after freeze-drying. Martin et al. (2013) also indicated that the EY for viable cells was significantly higher for microcapsules blending alginate with starch $(97.26 \%)$ than for microcapsules without starch (74.41\%). Gum arabic also has the added advantages of providing the health benefits associated with dietary fiber for use in the probiotic food industry (Desmond et al., 2002). According to these results, Al-GA was selected for further stability assays.

\section{Microcapsule morphology}

The surface morphology of the microcapsules was observed by optical and scanning electron microscopy. As

Table 2. Effect of coating materials on the protection of viable cell during freeze drying and encapsulation yield

\begin{tabular}{|c|c|c|c|c|}
\hline \multirow{2}{*}{ Wall materials } & \multicolumn{2}{|c|}{ No of cell encapsulated (CFU/g) } & \multirow{2}{*}{$\begin{array}{c}\text { Encapsulation yield } \\
(\%)\end{array}$} & \multirow{2}{*}{$\begin{array}{c}\text { Particle size } \\
(\mu \mathrm{m})\end{array}$} \\
\hline & Before freeze-drying & After freeze-drying & & \\
\hline $2 \%$ alginate & $10.06 \pm 0.11^{\mathrm{a}}$ & $10.24 \pm 0.07^{\mathrm{a}}$ & $93.90 \pm 1.5^{a b}$ & $18.46 \pm 0.23^{\mathrm{a}}$ \\
\hline $1 \%$ alginate $+1 \%$ gellan gum & $10.18 \pm 0.05^{\mathrm{a}}$ & $9.04 \pm 0.11^{b}$ & $82.84 \pm 2.7^{b}$ & $18.41 \pm 0.21^{\mathrm{a}}$ \\
\hline $1.5 \%$ alginate $+3 \%$ gum arabic & $10.12 \pm 0.13^{\mathrm{a}}$ & $10.70 \pm 0.05^{\mathrm{a}}$ & $98.11 \pm 0.8^{a}$ & $20.87 \pm 0.24^{\mathrm{a}}$ \\
\hline
\end{tabular}




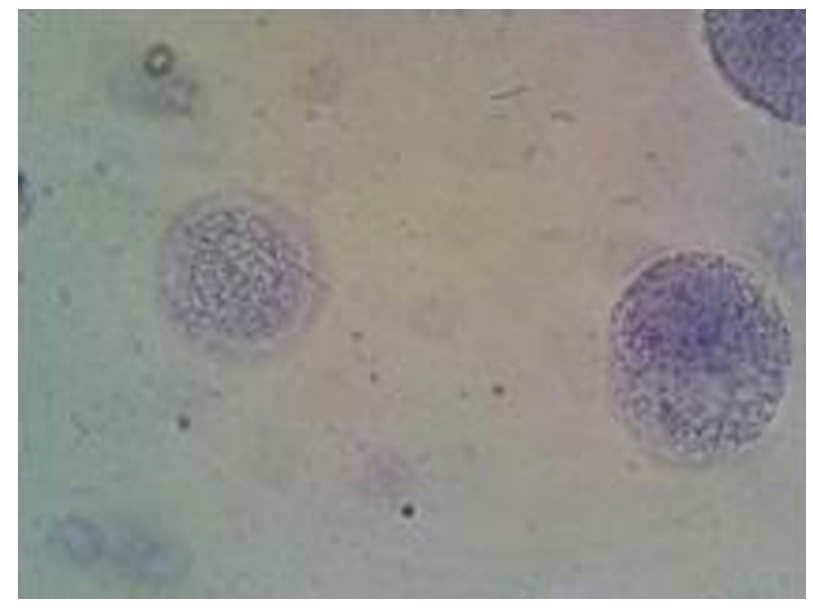

Fig. 1. Photomicrographs of Al-GA (1.5\% alginate $+3 \%$ gum Arabic) microcapsule observed through an optical microscope at $1,500 \times$.

shown in Fig. 1, microcapsules observed using an optical microscope were spherical in shape and isolated without adherence to each other. A spatial distribution of cells within the microcapsules was observed at a higher magnification micrograph.

To study the surface and porosity of the microcapsules containing probiotics and cell distribution inside capsules, intact microcapsules and fractured microcapsules were observed using a scanning electron microscope (SEM), respectively. The SEM photograph of Al-GA microcapsules (Fig. 2a) showed generally spherical shapes with wrinkled and rough surfaces. According to Lee et al. (2004), alginate microparticles usually have a heterogeneous structure with a dense surface layer and a loose core due to the heterogeneous gelation mechanism. In addition, some cracks were observed on the surface of the capsules, possibly caused by partly collapsing the polymeric gel network during drying (Nayak et al., 2012). The interior of the microcapsules was composed of a mesh-like structure of wall materials through which the bacterial cells were distributed (Fig. 2b). Martin et al. (2013) indicated that the occurrence of 'void space' phenomenon, the formation of cavities in the matrix, was because of the presence of bacteria in these spaces during gelation. However, void space phenomenon was not observed in this study.

\section{Acid and bile tolerance}

Following consumption, microorganisms must survive a transit through the gastric environment and reach the colon in quantities large enough to facilitate colonization. The harsh conditions of the gut, including the acidic nature of the stomach and the presence of bile in the intestine, can adversely affect the viability of probiotic cultures (Desmond et al., 2002; Koo et al., 2001). Although bile tolerance is often used as a criterion for probiotic strain selection (Krasaekoopt et al., 2004), bile salt solution was used here to determine whether the encapsulation technique used in this study would increase survival of cells in an environment similar to that of the digestive system.

Table 3 shows the survival of L. plantarum DKL 109 loaded in Al-GA microcapsules as a function of time after sequential incubation in AGJ of $\mathrm{pH} 2.0$ without pepsin followed by AIJ of $\mathrm{pH} 7.0$ with bile acid. When free cells were exposed to AGJ, the viable counts declined $5 \mathrm{log}$ cycles after 1 h. No L. plantarum DKL 109 survived after $2 \mathrm{~h}$ incubation due to its low acid resistance. On the other hand, the population of encapsulated cells was well maintained under sequential incubation in AGJ and AIJ. Other studies (Koo et al., 2001; Krasaekoopt et al., 2004; Sohail et al., 2011) also reported that the survival of probiotics microencapsulated with alginate alone or mixed with other coating materials was higher than that of the free cells.

While sequential incubation in AGJ and AIJ, the release profile of the encapsulated cells was observed by optical microscopy. As shown in Fig. 3, the microcapsu-
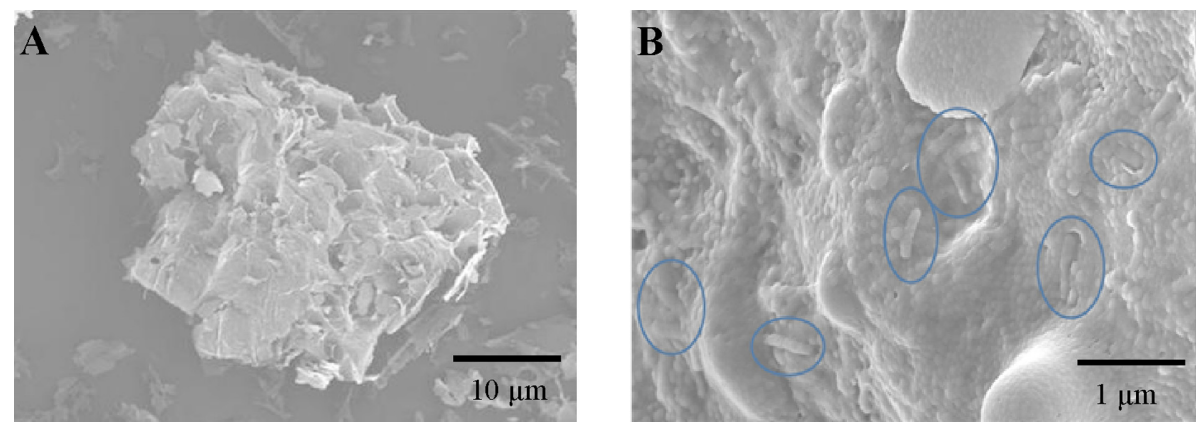

Fig. 2. SEM images of microcapsule Al-GA (1.5\% alginate + 3\% gum Arabic) microcapsule: (A) whole microcapsule at $1,000 \times$, (B) micrograph of shattered microcapsule with microbial cells inside at 5,000× (cells are shown in the circle). 
Table 3. Survival of encapsulated cells and free cells after sequential incubation in artificial gastric juice (AGJ) and artificial intestinal juice (AIJ)

\begin{tabular}{cccc}
\hline \hline \multirow{2}{*}{ Treatment solution } & \multirow{2}{*}{ Treatment time $(\mathrm{h})$} & \multicolumn{2}{c}{ Cell count (CFU/mL) } \\
\cline { 3 - 4 } & & Encapsulated cell & $11.04 \pm 0.11$ \\
\hline Artificial gastric juice & 0 & $11.11 \pm 0.03$ & $5.77 \pm 0.04$ \\
$(\mathrm{pH} 2.0)$ & 1 & $10.72 \pm 0.05$ & ND \\
\hline Artificial intestinal juice & 2 & $10.68 \pm 0.08$ & ND \\
$(\mathrm{pH} 7.0)$ & 3 & $10.41 \pm 0.02$ & ND \\
\hline
\end{tabular}

$\mathrm{ND}$, not detected.

Values shown are means \pm standard deviations $(n=3)$.
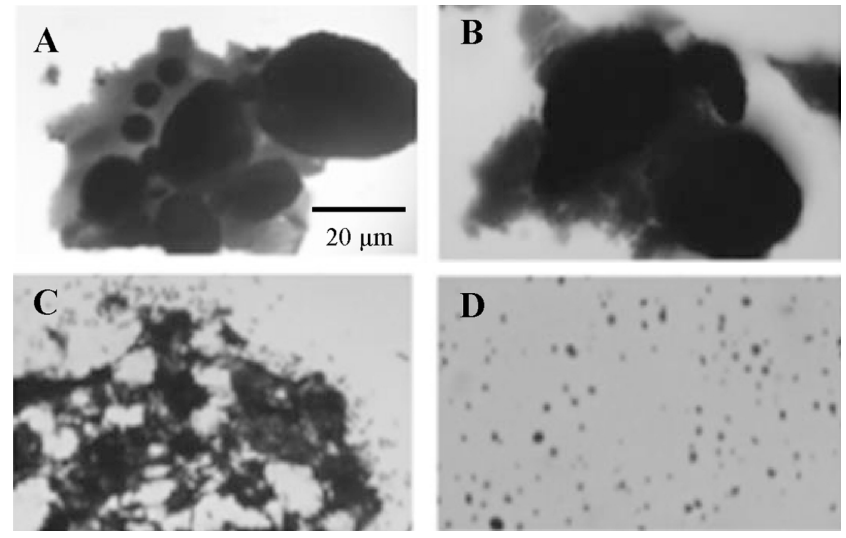

Fig. 3. Release profile of encapsulated cells during sequential incubation in artificial gastric juice $(2 \mathrm{~h})$ and artificial intestinal juice $(3 \mathbf{~ h})$. A: before incubation, B: after $2 \mathrm{~h}$, $\mathrm{C}$ : after $3 \mathrm{~h}, \mathrm{D}$ : after $5 \mathrm{~h}$.

les remained in a uniform spherical shape when incubated in AGJ, whereas the microcapsules became broken in AIJ. The burst release of L. plantarum DKL 109 happened after 1-h treatment in AIJ (total 3-h treatment), and then all encapsulated cells were released after total $5 \mathrm{~h}$ treatment. Kanmani et al. (2011) observed that alginate-chitosan coated capsules maintained their shape in AGJ and then became wrinkled and broken when incubated in AIJ for $144 \mathrm{~h}$. Sabikhi et al. (2010) observed similar release profiles in AIJ to our finding in which the complete release of encapsulated cells in alginate-starch microspheres in AIJ required 2.5 h. However, Shi et al. (2013) reported complete dissolution of carrageenan-locust bean gumcoated milk microspheres within 45 min when subjected to AIJ. Thus, the release profiles of the microcapsules were highly affected by the coating materials.

\section{Storage stability of encapsulated cell}

Cell viability during storage was monitored for $4 \mathrm{wk}$ at 25 and $37^{\circ} \mathrm{C}$ (Fig. 4). The viable cell count of the encapsulated cells remained stable through the storage period at
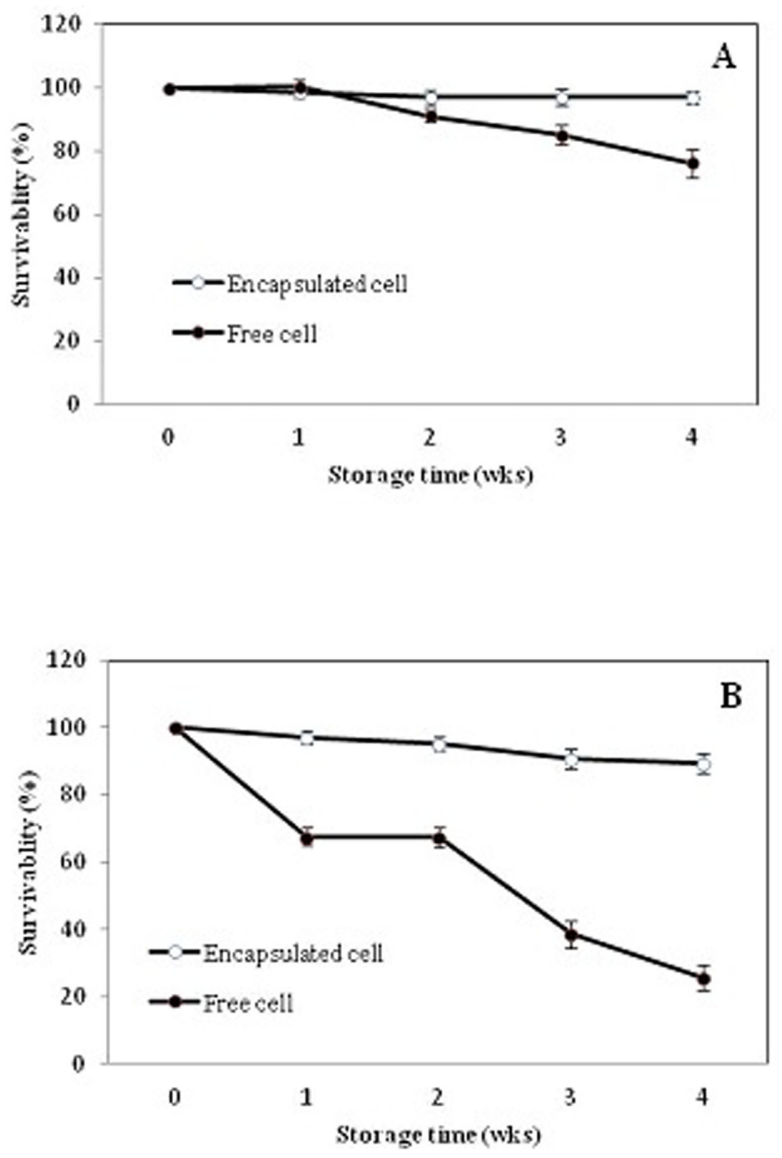

Fig. 4. Changes in survivability during storage of encapsulated cells and free cells stored at room temperature (A) and stored at $37^{\circ} \mathrm{C}(\mathrm{B})$.

ambient temperature while the survivability of the free cells started to decline after $2 \mathrm{wk}$ and showed $20 \%$ reduction after $4 \mathrm{wk}$ (Fig. $4 \mathrm{~A}$ ). At $37^{\circ} \mathrm{C}, 80 \%$ reduction in the free cells was observed. On the other hand, the survivability of the encapsulated cells was slightly decreased and showed only $10 \%$ reduction after 4 wk of storage (Fig. 4B). These results are in agreement with the studies by Koo et al. (2001) in which the viability of microencapsulated Lactobacillus casei YIT 9018 with alginate and chi- 
tosan were relatively stable at $22^{\circ} \mathrm{C}$ for $21 \mathrm{~d}$. Zou et al. (2012) also reported that the survival of Bifidobacterium bifidum F-35 loaded in whey protein microcapsules produced by the TGase-induced gelation method decreased by less than 1 log cycle. In contrast, Martin et al. (2013) observed no viability of cells encapsulated with a mix of alginate and starch after $2 \mathrm{wk}$ of storage at room temperature. This could be due to the water activity of the coating materials, resulting in lower metabolic activity and better storage stability, and environmental humidity, being one of the deleterious factors in the survival of anaerobic bacteria (Martin et al., 2013; Zou et al., 2012). Several studies (Kailasapathy, 2006; Koo et al., 2001; Martin et al., 2013; Shi et al., 2013; Zou et al., 2012) reported that the viability of microencapsulated cells remained relatively constant at $4^{\circ} \mathrm{C}$ for more than $1 \mathrm{mon}$.

\section{Conclusions}

Microcapsules with mean particle size of $20 \mathrm{~mm}$ containing the probiotic $L$. plantarum DKL 109 were produced by external ionic gelation technology using an atomizing spray device comprising an air spray gun. The encapsulation efficiency was highly affected by the coating materials. The Al-GA microcapsule showed higher encapsulation efficiency (98.11\%) and provided better protection of viable cells during freeze-drying than that of the other combinations of coating materials. The results of the stability test under harsh conditions indicated that the coating materials and microencapsulation technology used in this study could protect $L$. plantarum DKL 109 from gastrointestinal conditions. The stability of the encapsulated cells was maintained during $4 \mathrm{wk}$ of storage at ambient temperature and $37^{\circ} \mathrm{C}$. Thus, external ionic gelation with Al-GA is suitable methods for protecting $L$. plantarum DKL 109 and for high probiotic encapsulation efficiency. Moreover, this technique was found to be simple, reproducible, economical, and easily controllable. Simplification of the procedure makes it suitable to scalingup for industrial scales. According to these results, the atomizing spray device of pilot scale was developed for industrial use. The optimization of process conditions to encapsulate probiotics using this device is in progress.

\section{Acknowledgements}

This research was supported by International joint technology development project, Junbook Institute for Bioindustry (JIB) in 2010.

\section{References}

1. Agnihotri, N., Mishra, R., Goda, C., and Arora, M. (2012) Microencapsulation-A novel approach in drug delivery: A review. Indo Global J. Pharmaceutical Sci. 2, 1-20.

2. Chandramouli, V., Kailasapathya, K., Peirisb, P., and Jonesb, M. (2004) An improved method of microencapsulation and its evaluation to protect Lactobacillus spp. in simulated gastric conditions. J. Microbiol Meth. 56, 27-35.

3. Cho, Y. H., Hong, S. M., and Kim, C. H. (2013) Isolation and characterization of lactic acid bacteria from Kimchi: Korean traditional fermented food to apply into fermented dairy products. Korean J. Food Sci. An. 33, 75-82.

4. Desmond, C., Ross, R. P., O'Callaghan, E., Fitzgerald, G., and Stanton, C. (2002) Improved survival of Lactobacillus paracasei NFBC 338 in spray-dried powders containing gum acacia. J. Appl. Microbiol. 93, 1003-1011.

5. Dong, Q. Y., Chen, M. Y., Xin, Y., Qin, X. Y., Cheng, Z., Shi, L. E., and Tang, Z. X. (2013) Alginate-based and proteinbased materials for probiotics encapsulation: A review. Int. J. Food Sci. Technol. 48, 1339-1351.

6. Gerez, C. L., Font de Valdez, G., Gigante, M. L., and Grosso, C. R. F. (2012) Whey protein coating bead improves the survival of the probiotic Lactobacillus rhamnosus CRL 1505 to low pH. Lett. Appl. Microbiol. 54, 552-556.

7. Kailasapathy, K. (2006) Survival of free and encapsulated probiotic bacteria and their effect on the sensory properties of yoghurt. LWT-Food Sci. Technol. 39, 1221-1227.

8. Kanmani, P., Kumar, R. S., Yuvaraj, N., Paari, K. A., Pattukumar, V., and Arul, V. (2011) Effect of cryopreservation and microencapsulation of lactic acid bacterium Enterococcus faecium MC 13 for long-term storage. Biochem. Eng. J. 5859, 140-147.

9. Koo, S. M., Cho, Y. H., Huhg, C. S., Baek, Y. J., and Park, J. (2001) Improvement of the stability of Lactobacillus casei YIT 9018 by microencapsulation using alginate and chitosan. J. Microbiol. Biotechnol. 11, 376-383.

10. Krasaekoopt, W., Bhandari, B., and Deeth, H. (2003) Evaluation of encapsulation techniques of probiotics for yoghurt. Int. Dairy J. 13, 3-13.

11. Krasaekoopt, W., Bhandari, B., and Deeth, H. (2004) The influence of coating materials on some properties of alginate beads and survivability of microencapsulated probiotic bacteria. Int. Dairy J. 14, 737-743.

12. Lee, J. S., Cha, D. S., and Park, H. J. (2004) Survival of freeze-dried Lactobacillus bulgaricus KFRI 673 in chitosan-coated calcium alginate microparticles. J. Agric. Food Chem. 52, 7300-7305.

13. Martin, M. J., Lara-Villoslada, F., Ruiz, M. A., and Morales, M. E. (2013) Effect of unmodified starch on viability of alginate-encapsulated Lactobacillus fermentum CECT5716. LWTFood Sci. Technol. 53, 480-486.

14. Nayak, A. K., Das, B., and Maji, R. (2012) Calcium alginate/ gum arabic beads containing glibenclamide: Development and in vitro characterization. Int. J. Biological Macromolecules 51, 1070-1078. 
15. Picot, A. and Lacroix, C. (2004) Encapsulation of Bifidobacteria in whey protein-based microcapsules and survival in simulated gastrointestinal conditions and in yoghurt. Int. Dairy $J$. 14, 505-515.

16. Reis, C. P., Neufeld, R. J., Vilelas, S., Ribeiro, A. J., and Veiga, F. (2006) Review and current status of emulsion/dispersion technology using an internal gelation process for the design of alginate particles. J. Microencapsulation 23, 245-257.

17. Rosas-Flores, W., Ramos-Ramirez, E. G., and Salazar-Montoya, J. A. (2013) Microencapsulation of Lactobacillus helveticus and Lactobacillus delbrueckii using alginate and gellan gum. Carbohydr. Polym. 98, 1011-1017.

18. Sabikhi, L., Babu, R., Thompkinson, D. K., and Kapila, S. (2010) Resistance of microencapsulated Lactobacillus acidophilus LA1 to processing treatments and simulated gut conditions. Food Bioproc. Technol. 3, 586-593.

19. Shi, L. E., Li, Z. H., Zhang, Z. L., Zhang, T. T., Yu, W. M., Zhou, M. L., and Tang, Z. X. (2013) Encapsulation of Lactobacillus bulgaricus in carrageenan-locust bean gum coated milk microspheres with double layer structure. LWT-Food Sci. Technol. 54, 147-151.

20. Soccol, C. R., Vandenberghe, L. P., Spier, M. R., Medeiros,
A. B. P., Yamaguishi, C. T., De Dea Lindner, J., Pandey, A., and Thomaz-Soccol, V. (2010) The potential of probiotics: A review. Food Technol. Biotechnol. 48, 413-434.

21. Sohail, A., Turner, M. S., Coombes, A., Bostrom, T., and Bhandari, B. (2011) Survivability of probiotics encapsulated in alginate gel microbeads using a novel impinging aerosols method. Int. J. Food Microbiol. 145, 162-168.

22. Sohail, A., Turner, M. S., Coombes, A., and Bhandari, B. (2013) The viability of Lactobacillus rhamnosus GG and Lactobacillus acidophilus NCFM following double encapsulation in alginate and maltodextrin. Food Bioproc. Technol. 6, 2763-2769.

23. Song, S. H., Cho, Y. H., and Park, J. (2003) Microencapsulation of Lactobacillus casei YIT 9018 using a microporous glass membrane emulsification system. J. Food Sci. 68, 195200.

24. Zou, Q., Liu, X., Zhao, J., Tian, F., Zhang, H. P., Zhang, H., and Chen, W. (2012) Microencapsulation of Bifidobacterium bifidum F-35 in whey protein-based microcapsules by transglutaminase-induced gelation. J. Food Sci. 77, M270-M277.

(Received 2014.7.3/Revised 2014.8.21/Accepted 2014.9.22) 